\title{
The Role of Critical Thinking in Fostering Professional Capacity for Pedagogical Students in Vietnam Nowadays
}

\author{
Nguyen Thi Nga \\ Faculty of Politic Theories and Civic Education \\ Hanoi National University of Education, Hanoi, Vietnam
}

\begin{abstract}
Improving the professional capacity of pedagogical students is an urgent issue facing pedagogical universities in Vietnam. Currently, the professional capacity of these students is not only shown in the teaching ability but also in the soft skills fostered and self-trained by students themselves during the university study process. This article clarifies the role and the importance of critical thinking in fostering professional capacity for pedagogical students in Vietnam nowadays.
\end{abstract}

Keywords: critical thinking, professional capacity, pedagogical students, role.

DOI: $10.7176 /$ RHSS/10-18-06

Publication date:September $30^{\text {th }} 2020$

\section{Introduction}

In the twenty-first century, the goal of building lifelong learning skills requires people to constantly develop critical thinking in any educational system. Critical thinking plays a crucial role in helping people to have deep and correct knowledge. At the same time, critical thinking also helps people to form the ability to build knowledge, diverse skills, good thinking in order to grasp knowledge and control it, as well as adapt to social changes. Thus, it can be seen that critical thinking plays an extremely important role in any educational achievement and is also a powerful tool for lifelong learning goals.

In many countries with developed education in the world, the priority to develop the competence of critical thinking becomes an essential requirement in improving the quality of education. However, the development of this skill in Vietnam has not been disseminated and respected. One of the substantial reasons is that teachers - the core force, playing a crucial role in the teaching process, do not have solid knowledge base about critical thinking as well as developing the capacity of critical thinking in the educational environment. That puts a heavy emphasis on the role of pedagogical universities - where a contingent of teachers will be trained and fostered in the future. Therefore, the development of critical thinking capacity for students of pedagogical universities in Vietnam is now extremely necessary. It contributes to the creation of prospective teachers with strong professional qualifications, as well as valuable educational achievements.

\section{History of studying the problem}

Do Kien Trung with his article "The role of critical thinking and teaching requirements in Vietnam" [11] affirmed that critical thinking or any other form of thinking belongs to the realm of human thought processes, in which, the human mind moves with the combination of emotions to make judgments and evaluate human activities before the effects of reality. The author also discussed and explained the need to build critical thinking proficiency in human cognitive activities and practical activities, especially with students.

Bui Ngoc Quan with the article "Critical thinking - the foundation for the development of creative thinking of students in universities and colleges today" [9] commented: Comprehensive education at the new stage needs to train people who are able to grasp and control knowledge to adapt to the change of society. That requires learners to have the ability to create knowledge, foster diversity, good thinking, and confidence. Therefore, modern education must build and develop students with basic competencies such as: creative thinking, critical thinking, problem solving capacity, etc. On the basis of analyzing the dialectical relationship between creative thinking and critical thinking, the author affirms that critical thinking lays the foundation for deep and systematic learning of students. Critical thinking is the foundation to develop students' creative thinking. Through critical thinking, students can evaluate and improve creative ideas, while at the same time helping them to have a positive outlook and look forward to new things. Moreover, critical thinking helps students to consider more accurately before solving a problem.

Nguyen Gia Cau with the article "Fostering and developing the capacity of critical thinking for students in the teaching process" [8]. The article has confirmed that educating and developing positive thinking for students is one of the most important tasks of the educational process and teaching process, in which, critical thinking is an important value of personality. Critical thinking is one of the most important skills determining whether learners will be successful or not. The author has deeply analyzed the role of critical thinking in the educational process and verified that critical thinking is an essential part of creativity. Only those who know how to counter-argue have creative ability. 
Nguyen Thanh Thi with the article "The need for training critical capacity in learning for students" [10] has affirmed the important role of critical thinking in many fields such as professional and academic, as well as other areas of social activities. The capacity of counter-argue is formed through the process of training, not a natural or innate ability. Therefore, through the subjects in class, teachers need to practice and improve students' counterargue ability. This must be done regularly and varied during regular school hours, after school hours, in class or outside school hours, etc.

Huynh Huu Tue with his article "Critical thinking in university studies" [12] asserted that learning helps students develop their intellectual life. Intellectual activity is the basis of the ability to think independently and critical thinking. According to the author, critical thinking plays a significant role in the learning process of students. With independent and critical thinking as the foundation, and with knowledge accumulated into a system, students will have the opportunity to expand their creative thinking.

\section{Main content}

\section{a. Critical thinking}

In the West, the basic idea that supports critical thinking was built by the Greeks about 2300 years ago. It is called the "syllogism rule" which was developed on the basis of arguments. Sokrates has focused on understanding and developing dialectical thinking as well as laying the cornerstone for rhetoric based on a system of conversational questions. Aristotle viewed the faculty of pure thought as a characteristic that defines human nature - a characteristic that distinguishes man from other animals. Descartes once described thinking as a universal tool that can be used in any situation. Thus, right from ancient times, Western philosophers have mentioned the spirit of counter-argument as a way of thinking to approach the truth. Similarly, in the East - India, in the Buddhist scriptures also mentions counter-argument as a way to enlightenment of the doctrine. In ancient China, during the Spring and Autumn period and the Warring States period, in the era of the "hundred schools of thought, hundred schools contend", philosophers in presenting their doctrines, often argued convincingly directly or indirectly other theories, although the counter-argument is not stated as a method of thinking. Therefore, it can be seen that critical thinking comes from the ability to reason and evaluate reasoning actively, continuously and carefully consider the information before making a decision.

There have been many scientists interested, researched and given different definitions of critical thinking. Mr. Kurfis, for example, said: "Critical thinking shows an openness to questions, views on a rich issue and not to be confused by a particular result" [2, p.10]. Or the point of view of D.J. Treffinger: "Critical thinking is shown in the careful, fair and constructive consideration of the probabilities of a given problem" [1, p. 23].

Although there are many different conceptions, they are unified in terms of content: Critical thinking is considered as a way of looking at the problem in many angles and the possibilities of the problem are examined carefully, meticulously, objectively and constructively. On that basis, scientists make the correct comments, assessments and decisions to solve the problem in a scientific and effective way.

Thus, it can be seen that critical thinking is a high-level thinking proficiency based on grounded arguments to analyze and evaluate an existing information according to different perspectives on the problem posed to clarify or reaffirm the accuracy of the problem.

\section{b. Professional competency of pedagogical students}

Competency is all about qualities, abilities, and characteristics of a person (both psychological and physiological) to ensure the performance of a certain activity. Currently, competencies are divided into many different categories such as: specialized capacity, methodological capacity, social capacity, individual capacity and professional capacity.

Pedagogical competency is a special kind of competency that is characteristic of a teaching profession. Pedagogical capacity is not only the teaching capacity but also includes many other competencies such as: understanding students, pedagogical communication, pedagogical behavior, etc.

Pedagogical students will be the teachers in future, from receiving subjects to transmitting subjects. Therefore, unlike students of other disciplines, students of pedagogy must actively practice and foster specific competencies and qualities of their careers [3, p.34].

Firstly, to become a teacher in the future, students must actively study, foster and improve their own knowledge and understanding [5, p.8]. They not only have to master their specialized knowledge but also have to constantly explore, cultivate and expand their knowledge, deep understanding in all fields of science, social life. Only then, after graduating from school, they can organize for students to recreate and regain what is needed for the development of students' psychology and personality, creating important foundations for finished products.

Secondly, pedagogical students are not only professional but need to practice and cultivate flexible, flexible teaching methods that are suitable for each student. Teaching methods of teachers play an important role in acquiring and occupying knowledge of students. In order to form and foster this teaching method, pedagogical students must experience the practical process and professional self-training, self-improvement through pedagogical internships, especially the skills such as: composing lesson plans, teaching practice, writing boards, 
designing teaching aids, organizing teaching, testing and evaluating students,.... The formation of the above competencies is not easy, but on the contrary, it is the result of a serious and elaborate process of learning and practice (in the school environment and after graduation).

Thirdly, students also have to practice other pedagogical competencies such as: understanding students, student chemistry, pedagogical communication, the ability to handle pedagogical situations ... These are the necessary competencies, the key for teachers to approach, understand, touch and orient students in the learning and educational process. It is the ability to "penetrate" into the inner world of the child, observe meticulously, understand, and empathize with the psychological feelings of the students to have the measures of pedagogical impact appropriate to the mental characteristics student age physiology. To teach and educate students must come from understanding their psychological developments through the proper use of linguistic and non-verbal media (eyes, smiles, gestures, gestures). , ...), from which gives the most correct pedagogical effects. This is the art of pedagogy.

Fourthly, students must cultivate and practice their proficient and skilled language abilities. It can be said that there is no teaching capacity without language proficiency. This is an important capacity, a vital tool of a teacher to perform his teaching and educational functions. Language capacity is the ability to clearly and coherently express one's thoughts and feelings with words as well as facial expressions and postures. A teacher's linguistic capacity is often expressed both in its content and form, so the teacher's language requirements must be deep in content and simple in form.

Fifthly, the specific profession of teachers not only captures and imparts knowledge to learners but also educates the way of thinking and thinking methods. This is a key factor to help learners apply the theoretical knowledge they have learned to solve specific problems in practice. To educate thinking methods and research methods for future learners, it requires pedagogical students to equip themselves, regularly train and foster necessary logical thinking abilities such as: dialectical thinking capacity, critical thinking capacity, creative thinking capacity, ... These thinking abilities help pedagogical students know how to think, analyze, evaluate, and solve problems that arise in the learning and research process. At the same time, regular practice and self-training will help pedagogical students have good logical thinking ability, well perform the tasks of the teacher in the future. c. The role of critical thinking in fostering professional competencies of pedagogical students

Firstly, critical thinking helps pedagogical students to receive and process information quickly and accurately. It also helps them to solve learning and research problems. To perform the teaching capacity in the future, these students need to equip themselves with an extremely rich and extensive knowledge base in many fields. Currently, pedagogical students can easily access and update new information from many different kinds of source and also in a variety of forms. Students not only get access to the information through lectures, documents and textbooks provided by the teachers, but they can also explore and update their knowledge through books, newspapers or on the internet, etc. The textbooks and lectures of teachers are not the only guidance for students but only a reference material. Therefore, the self-study process requires students to constantly explore and approach many different documents to get an overview of the research problem. That helps pedagogical students to master their knowledge, apply creatively that knowledge in solving practical problems. It also brings high efficiency in the process of selfstudy and creates a solid foundation of knowledge and skills, along with forming and fostering teaching capacity on them.

Secondly, critical thinking helps students to practice their ability to detect and solve pedagogical situations and foster their ability to behave properly. Critical thinking recognizes and evaluates problems based on the rules of logical thinking and scientific bases and it also requires a comprehensive standpoint. That trains pedagogical students to have a comprehensive and multidimensional view when considering and solving any pedagogical situation that arises in the learning and research process. By doing all of these, after graduating from school, pedagogical students can educate the future generations and evaluate people without being dominated by a subjective and single sided view. To form and develop a person's personality is a long educational process and it must be considered by a comprehensive perspective. All subjective conclusions, which are derived from negative and one-sided views, are the results of unfounded and impatient perceptions, and thereby lead to misjudging facts or people.

Thirdly, critical thinking helps pedagogical students to foster the habit of positive thinking, to have a multidimensional perspective, tolisten and respect the opinions of others and also to respect the differences. That has a crucial meaning in preparing a long-lasting knowledge for pedagogical students after graduation to be able to work smoothly. In order to achieve the noble educational task in the future, pedagogical students need to listen and respect the opinions of others, especially respect the differences. These are extremely necessary and important skills to help these future teachers form and foster their ability to understand students, thereby moving towards student changes. Listening to others, respecting differences, and eliminating prejudices will create an equal, fair and inclusive educational environment.

Fourthly, critical thinking helps pedagogical students to form their presentation and rhetoric skills. Presentation and rhetoric are two extremely important skills that need to be formed, trained and regularly fostered 
for students of pedagogical universities. These are two essential skills that are indispensable for any teacher. Each teacher's lecture is an eloquent presentation with well-grounded arguments, convincing students on the basis of clear analysis and easy to understand. A successful speech requires pedagogical students not only to have a certain understanding of the problem posing, but also on that basis to give their own views in a convincing and wellgrounded way with clear thesis. It requires students to confidently express their own thoughts and opinions and they also have to know how to use the manipulation of logical thinking, dialectical thinking, critical thinking, etc.

Finally, critical thinking helps pedagogical students to be ready to accept the new, to perceive their own mistakes and limitations, to absorb the contributions of others. The ones who think critically will work on grounded and objective analysis and assessments, not on their self-esteem. Therefore, they may be willing to acknowledge their limitations, correct their mistakes, listen and respect the opinions of others, which makes them easier to get close to others, be sociable and get sympathy from those around them. This is also one of the important pedagogical skills for teachers to be able to understand and win the hearts of their students.

\section{Conclusion}

There is a significant contribution of critical thinking capacity in achieving high results in the comprehensive innovation of education as well as the learning and training process of pedagogical students in Vietnam. Due to the specificity of the profession, pedagogical students need to practice, improve, master the skills of critical thinking capacity such as: receiving information, processing information, discovering new problems, as well as making quick and accurate decisions to best solve the problem. The development of critical thinking ability helps pedagogical students to have a multi-dimensional view, recognize and evaluate problems based on convincing arguments. It also helps them to be confident, brave and prepare the professional competencies needed to undertake a teaching career in the future.

\section{List of references:}

1. Donald J. Treffinger (2009), Preparing creative and critical thinkers, ADSL, USA.

2. University of Wollongong (2001), Critical Thinking, Self directed learning resource, Learning Resource Center and Learning Development, PDF format.

3. Hoang Anh (1991), About some communication skills that have been formed in pedagogical students, Journal of Educational Research (7).

4. Nguyen Thanh Binh (1991), On the communication needs of pedagogical students, Journal of Educational Research, (6).

5. Ministry of Education and Training (2005), Project on building and improving the quality of the contingent of teachers and educational administrators 2005-2010.

6. The Ministry of Education and Training (2009), Circular promulgating the regulations on the professional standards of middle and high school teachers, No. 30/2009 / TT - BGDĐT

7. Ministry of Education and Training (2011), Program for the development of Pedagogy and Pedagogical Schools from 2011 to 2020, No. 6290 / QD-BGDĐT

8. Nguyen Gia Cau (2013), Fostering and developing the capacity of critical thinking for students in the teaching process, Education Journal (13).

9. Bui Ngoc Quan (2016), Activate teaching activities of lecturers in training critical thinking for students, Education Journal (377)

10. Nguyen Thanh Thi (2013), The need for training critical capacity in learning for students, Culture and tourism Journal (13).

11. Do Kien Trung (2012), The role of critical thinking and teaching requirements in Vietnam, Journal of Development and Integration (5).

12. Huynh Huu Tue (2010), Critical thinking in university studies, Hanoi National University Bulletin (232). 